\title{
Factors Influence on Packaging Design in an Impulse Consumer Purchasing Behavior: A Case Study of Doritos Pack
}

\author{
Alaeddin Mohammad K. Ahmad ${ }^{1} \&$ Qais Mohammad K. Ahmad ${ }^{2}$ \\ ${ }^{1}$ Faculty of Economics and Administration, King Abdul-Aziz, University, Jeddah, Saudi Arabia \\ ${ }^{2}$ MA Communication Design, Salford University, Manchester, UK \\ Correspondence: Alaeddin Mohammad K. Ahmad, Faculty of Economics and Administration, King Abdul-Aziz, \\ University, Jeddah, Saudi Arabia. Tel: 966-56-852-7444. E-mail: amahmed1@kau.edu.sa or \\ aladdin.a.h@hotmail.com
}

Received: September 1, 2015

Accepted: October 6, 2015 Online Published: November 30, 2015

doi:10.5539/ijms.v7n6p92

URL: http://dx.doi.org/10.5539/ijms.v7n6p92

\begin{abstract}
The conventional role of packaging in buyer products has been to save and protect the product. In fact these days, buyer and manufacture trends propose a progressively significant part for packaging as a tactical tool as well as a marketing strategy. This research aims to investigate the impact of factors influence on packaging design in an impulse purchasing circumstances as a case study of Doritos pack in Manchester city-UK. This research consists of the independent variables represented by visual components and informational components namely (pack graphics, layout, color, photography and illustration, typography, pack size and shape; product information, and package technology) and dependent variable which represented by impulse purchasing behavior. In order to explore the relationship between independent and dependent variables the qualitative method was used to collect primary data through a social media, online, and face to face interviews, which was administered with customers and experts in product innovation. The research sample in this research consists of 34 participants and an expert in product innovation. The results confirm that for most participants in the interviews, the factors which influence on the bad image of current Doritos chips bags in the marketplace are; protection, communication, and information. The research concludes that there are many functions to packaging design in order to ease and communicate with customers; increasingly, there is important role of packaging as a strategic tool to attract consumers' attention and their perception on the product quality. Brand has important role in identify layout, graphics, color, and typeface. The new packaging design mostly uses the brand in products. Mainly, the packaging design includes all printed information such as made it, where it was made, when it was made, what it contains, how to use it. Moreover, the printed information is given in the brand and its value has to be showed while promoting the product in the market.
\end{abstract}

Keywords: packaging design elements, consumer purchasing behavior, Doritos, UK

\section{Introduction}

The most enchanting concept of marketing is to identify the understanding of the logic of consumers. Despite costly hazards of impulse shopping, buyers are increasingly making their buying decisions in markets. Many recent studies have shown the design of pack can make competitive advantage by adding high value, improving the product, creating stronger shelf impact, putting a brand in a special way, and improving brand's relationship with the consumer. The competitive markets depend on the significant role of package as one of the tools of the sales promotion. For instance, "packaging design appeals consumer's attention to a special trade mark and encourages the product image, and affects consumer's views about product" (Rundh, 2005). And also package confers value to products (Underwood, Klein, \& Burke, 2001; Silayoi \& Speece, 2004).

There is no doubt that it is important to acknowledge that marketers absolutely have to study the market well before they make decisions and lunch the product; because it is simply able to give a penetration and the overwhelming success. However, assuming that package is not successful in the market and is not work as how required, it certainly gives a bad image of the product even if the product itself has a high value, for that reason; there is nobody decides to purchase this product. Having an attractive packaging design will persist to work for market and product itself for long time, which will support to build a huge amount of public and dramatically increase the loyalty to the product. 
The motivation behind the study was the desire to discover and understand the factors that influence consumer behaviour through presenting an attractive packaging in an impulse purchasing circumstance as a case study of Doritos pack. Hence, the study aimed to answer on the comprehensive question 'How do Doritos packaging design influences on the impulse purchase decision?'. First and foremost, this case study identified the factors which influence on the bad image of Doritos chips bags in the marketplace. Second, determined the methods of designing a new packaging to keep and protect Doritos chips from damage and breaks. The third was to raise awareness of the shelf impact on building the Doritos brand in the marketplace.

The research started with a literature review in order to develop the findings of previous experiments and investigations. The literature review covered two main areas; the packaging design elements and consumer purchase behaviour. Request is sent to Doritos Company to gather more information about the criteria used in design a new pack, survey, and target market (e.g., at whom do you target the new design?).

Despite the lack of information obtained from Doritos Company, but the research found valuable information from a various sources, such as some documents and case study of Doritos (Bags of fun) by Daniel Bone. In this view, thirty four took part in the interview to explore the important factors that influence on consumer purchase behaviour through buying Doritos bags. And also the research included an in-depth interview a specialist in product innovation at Salford University.

\section{Literature Review and Context}

To more deeply explore the factors that influence consumer purchase behaviour through presenting an attractive packaging design in an impulse purchasing circumstance, the literature derived from previous studies in the field of packaging design, marketing communication and impulse buying.

According to Mel Byars and Alexander Gelman (2000) "The best and worst human characteristics that foster excellence may arguably be obsession and ego". Alexander believes that "obsession with the graphics components combines with designer individual egos to create the best possible solutions".

\subsection{Packaging Design Elements}

There are many notions and ramifications of the packaging design concept and its elements, For example, surface graphics, illustration, color, typography, material, symbols and icons, brand, and size (Underwood et al., 2001). To conduct packaging design elements, there are a various different points of views which will be shown off. According to Ampuero and Vila (2006) classified that distinctive packaging design into two components:

Graphics components: For example, surface graphics, illustration, branding, color, typography, information layout and so on.

Structural components: For example, materials, size, shape, and innovative formats.

On the other hand Silayoi and Speece (2004) have a different opinion from Ampuero and Vilas (2006) through divide packaging components into two categories. According to Silayoi and Speece (2004) assume that there are four main packaging elements possibly influence consumer purchase decisions and they could be divided into two categories:

Visual components: The visual components include surface graphics, packaging size and shape, and in short all effective components which play a significant role in buying decision making (Silayoi \& Speece, 2004).

Informational components: All packaging displays information to a greater or lesser degree. Typically, this information can be divided into different types, such as branding, naming, and features and benefits (Silayoi \& Speece, 2004). 


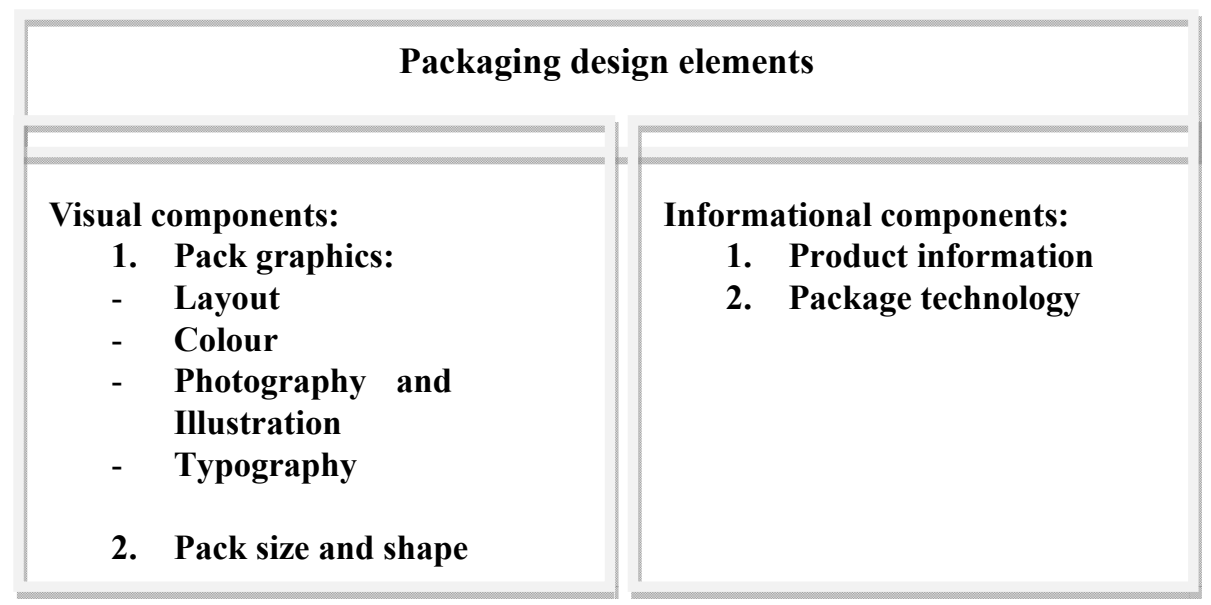

Figure 1. Packaging design elements (Silayoi \& Speece, 2004)

It is immediately obvious the figure shows the two sorts of packaging design: visual and informational. On one hand visual components are sorted into two sorts: pack graphics, and pack size and shape. Pack graphics consist of layout, illustrations, color, and typography. On the other hand informational components are also sorted into two sorts: product information and package technology. It is important to show how these components can be work in packaging design.

\subsubsection{Visual Components}

\subsubsection{Package graphics}

The visual form of packaging design is different from one package to another, whether the difference graphical element or size and shape. Moreover, as previously mentioned, graphic elements such as color, illustration, typography, and layout, all these elements and more can create one unit product (Silayoi \& Speece, 2004). According to Silayoi and Speece (2004) believe that "lack of graphics in package can waste the sale for many customers. As well as appealing graphics increases the sales as much as possible. For example, the colourful package can appeal consumers to buy".

Moreover, pack design is demanded to appeal and develop as markets constantly move away from existing products (Garber et al., 2000; Schoormans \& Robben 1997). There are many elements of the graphics mix can get lost in the competitive markets where each attracts for your attention. For example, Packs such as Heinz are sometimes called trigger packs because there is a little dialogue other than the announcement of strong (Smith \& Taylor, 2004).

In the same way as a package graphics, some previous research has explored that oblique packages attract attention. Other studies show that oblique package colors and shapes appealing consumers (Garber et al., 2000; Schoormans \& Robben, 1997). On the other hand, images on packages can attract attention especially in some cases when the customer experience is less than normal with a particular brand (Underwood et al., 2001). Also previous studies have concentrated on other cases than images on packages, other studies have found that one package attracts as colors (Gordon et al., 1994).

\section{$\underline{\text { Color }}$}

Color is considered as one of the package graphics elements. Albert Kner believes that "Color is the quickest path to the emotions". And also believes that "words must be transformed into images". Color often gives the viewer a secret and can control the emotions. Russia's Pedagogical Institute has found that "most people can feel color and can create a physiological response" (Smith \& Taylor, 2004).

According to the Luscher color test, they applied an experiment on some people. This experiment used color cards to analyse the reader's physiological, and exactly emotional. Colors have meaning for people as a result of the Luscher color test and lots of people associate colors with images. For example, there was a group of people who link the green color with 7UP (Smith \& Taylor, 2004).

Meyers-Levy and Peracchio (1995) assumed that "vivid color can attracts attention more than black and white color, and also can supply any information in brilliant way to ease these information on the reader". One study 
take a part of color assumed that product can come into view the chaos of owning brands in relation to achieve the desired aim and also color considers a huge factor in order to appeal the consumer (Bone \& France, 2001).

As previously mentioned, Color has different meanings in different cultures. And also color has a very versatile in everyday life through the theory of color. However, Ampuero and Vila (2006) stated that "some colors can be exceeded all distances". In line with this project, Ampuero and Vila (2006) explored that "pack in dark and cold colors in the past were consistently related with an expensive prices and duplicate aesthetics". On the other hand, some consumers require dairy products that directed to price through light, neutral color, primarily white, and colored package. For example, some people believed that red packaging color was connected with safe and guaranteed products.

\section{Layout}

There are many challenges facing the designer when create the layout of package and display the information to the consumers into a distinctive way, so these features can be supported brands and interestingly these can provide the customers many options to choose product in easy way. For instance, when Lewis Moberly was commissioned to redesign Limits' packaging, the visual language of the meal replacement category had become a cliché. Anaemic white packs with washed out colors simply communicated diet without any reassurance that the product was either enjoyable or effective. In contrast, "Limits' packaging features mouth-watering photography, and dramatic black banding that differentiates it on shelf" (Calver, 2004).

Furthermore, according to Rettie and Brewer (2000) the layout has many problems as they reported the recollection of packaging parts. As a reason, Rettie and Brewer discovered that "packaging parts were remembered in a different way according to their placement on the packaging design". The findings display that "spoken stimulus is remembered best when they are on the correct side of the visual field, and non-spoken stimulus remember would be best when on the wrong side of the visual field". Therefore, the composition of communication parts can be thought to impact both the product associations and product recollection (Rettie \& Brewer, 2000).

\section{Photography and Illustration}

Imagery is a constant in different type of packaging design, as a result of it send immediately the messages to consumers, powerful, and long-lasting. And also imagery can communicate it quickly and effectively. In some cases, the purpose of the photograph is interpretation, showing the consumers what is contained within the package (Calver, 2004).

According to (Silayoi \& Speece, 2004) considered that image is the third graphical package element. For example, MacInnis and Price (1987) assumed that consumers prefer to see a product image on a package more than imagine how a product looks, tastes, feels, smells, and sounds. Yattendon exemplifies the authentic image on a bake bread. Yattendon is a huge farming estate with a flourishing village. Its packaging features real characters who work in the village. The photographs not only root the breads in a very real English tradition but give the product authenticity. Designed by Alter Works in collaboration with product specialists Factory Design (Calver, 2004).

In ancient world, illustration were the essentially method of featuring an image on packaging. In contrast, the invention of photography, and the development of printing technologies resulted in illustration being used less repeatedly. However, may be because illustrations have with them meanings of craft and traditionalism (Calver, 2004).

\section{Typography}

The fourth element of graphical package elements is Typography. Typography considers the heart of packaging design as a result; it is primarily concerned with giving out information. In addition to products have names, description, uses, instructions, customer care information, and ownership details. The designer's skill lies in matching typeface selection to function. Selection is determined by factors like package size, information extent and printing methodology (Calver, 2004).

Some previous studies found that typography in package can convert a great image about elegant products through presenting bold, large, roman, upper case letters with expanded characters (Ampuero \& Vila, 2006). But the accessible products of reasonable price were connected with both serif and sans serif typographies (Ampuero \& Vila, 2006). For example, the simple but wonderful typeface twist to the ' $\mathrm{g}$ ' conveys so much about the Spanish provenance of the bottle of wine. And also it is simplicity makes it stand out in a crowded marketplace (Calver, 2004). 


\subsubsection{Size and Shape}

Silayoi and Speece (2004) classified the size and shape as the second kind of Visual components. According to the two authors, the size and shape of package attract consumer evaluation and decisions, such as graphical components, but not as usual in easily uncovered ways. Silayoi and Speece (2004) found from their study that size and shape were much associated to usability. Whilst consumers considered of product images and graphics as a methods of communication, discussion about size and shape concentrated more on packages being convenient to use and carry (Silayoi \& Speece, 2004).

It is important to acknowledge that shape plays a significant feature as evidence from the previous studies which talked about some shapes of package that can be in marketing tool. For instance, some brands have a distinctive package shape that they are considerable from the shape alone (Smith \& Taylor, 2004). However, shape attracts the protection and convenience functions in holding, pouring, and storing. A great designed package fits the hand more comfortably and creates what Coca-Cola proudly say 'in-hand embellishment' (Smith \& Taylor, 2004).

For instance, the size and shape of Coca-Cola cans used to be its visual identity. One study analyse the different shapes and sizes of soft drinks like Fanta, Sprite, and Pepsi, it found that many companies have various forms of the cans. In contrast, size of the package could be designed in a different style to give the product shelf space and creates its own unique identity (Silayoi \& Speece, 2004).

On the other hand, some studies said size communicates. Large package communicates better quality. For example, large cereal packages make feelings of plentiful, expansive, energy giving food whereas a smaller pack may make the cornflakes seem heavy, solid, and not good (Smith \& Taylor, 2004).

\subsubsection{Informational Components}

Silayoi and Speece (2007) divided Informational components into two types: information provided by the package and technologies used in the package.

\section{Product Information}

The product information is considered the most essential core that customers are looking for in many different sources. Customer is always expected a valuable and rich information to make purchase decision (Riversand, 2014). While those responsible for brands must make all products information obvious and clear as a result of increase the consumer loyalty. Moreover, Silayoi and Speece (2007), studied the consumers behaviour were found that consumer use clear product information to evaluate healthiness, and also many other issues of quality.

\section{Package Technology}

The main goal of package is protect products and contents from break and damage during storage, transport, and usage. Some packages have to protect the consumer from the contents. For example, some cases of children with weed killer, medicine, and any dangerous contents. Dramatically, some packages must to protect the contents from tampering. For instance, six people died in Chicago when Johnson and Johnson's Tylenol pain relievers were laced with cyanide (Smith \& Taylor, 2004).

Hence, there are many significant factors to reduce the presence of chemicals impact of oxygen in shelf life of perishable foods like meat, poultry, fish, eggs, fruits, vegetables, and baked products. Each of these factors must take part in any of packaging improvement and also the results in changes in colour need further consideration (James et al., 1990).

\subsection{Consumer Purchase Behaviour}

Paul Smith (2004) has suggested that purchasing decision rationally happens in rare cases. But the external shape of the package plays an important role to choose any product. Actually the consumer is faced a several of thousand packs shouting out 'buy me' through high quality design which gives a mystery to choose. Ernest Dichter (1964) assumed that distinct designed pack usually can positively contribute in the choice.

Rita Kuvykaite (2009) has believed that package considers a significant role in "marketing communications and could be treated as important factor which influencing consumer's buying of package", the package aspects and their powerful effects on customer's purchasing behaviour started to be connected in some way with issue. In the study conducted by John Gersen (2000) talked about ethical consumer. The study shows the moral norms for choosing packaging design. The study conducted in a case of two different characteristics: Danish consumer's choice of environment-friendly packaging. The results found that majority of Danish consumers choose environment-friendly in the stores (John, 2000). 


\section{Scope of Study}

The packaging design has to develop into a more advanced and change into a stronger form. The packaging design needs to return changes in the customer's aspirations through exploit new technology to improve the package in modern way (Smith \& Taylor, 2004). The good designed package can lead to control the consumers to make purchase decision and buy the product (Sogan \& Ostli, 2009).

By conducting the literature review, the investigation has shown that there is agreement on classification of packaging components as well as on research methods of factors that influence consumer purchase behaviour through presenting an attractive packaging in an impulse purchasing circumstance. Moreover, the redundancy of scientific literature on this field provides the same mind of answer concerning influence consumer purchase behaviour through presenting an attractive packaging in an impulse purchasing circumstance. The various results in this field depend on point out technical and methodological flaws in the study (Cooper, 2010). For that reason, it is very important to investigate this study in more detail.

\section{Methodology}

"Not everything that can be counted counts and not everything that counts can be counted" (Albert Einstein). As the researcher begin research, it will be important to think about where you want this research to take you. It is effective to start thinking about methodology early in your research project; it is useful to see a map for the research journey. It will guide you in the whole project, beginning with data collection through data analysis to the final report (Crouch \& Pearce, 2012).

\subsection{Study Approach and Methods}

As this study starts setting out with the aim of understanding the factors that influence consumer purchases behaviour through presenting an attractive packaging in an impulse purchasing circumstance. Because the study focus is clearly defined to develop or redesign a new Doritos package in an attractive way to increase sales, the research decided to use methodological triangulation which means using more than one method to gather data on the same topic which involves sorts of samples as well as methods of data collection. The purpose of methodological triangulation is to capture various dimensions of the same phenomenon (Thurmond, 2001).

According to Flick (2009) triangulation conducted case study approach to resolve this problem in order to develop a profound understanding of the case, qualitative research method was adopted in this study to understand the experiments and attitudes of participants through conducted semi-structured interview, one-to-one interview.

Furthermore, this study used a visual data such as photos and videos in order to extend the integrated perspectives on the subject. According to Harper (1998) said "The images were arranged in groups that allowed several perspectives on a single subject to be presented simultaneously or in sequences that showed how a social event evolved through time" (Wolff, 2004, p. 284). In addition to used documents as data such as case study about Doritos bag and Nestle.

\subsection{Study Sample}

Sixteen participants over 18 years of age and different nationalities who are Doritos fans in Facebook were conducted the interview. While eleven participants were recruited face to face interview in different places, five participants were enlisted online interview in order to complete a seven questions interview which took approximately 15 minutes. According to Creswell and Merriam (2009) assumed that small studies serve the researcher to get in-depth understanding of participant experiment and to increase a worth description of that experience.

As a part of the case study there were two expert interviews with a specialist in product innovation and associate professor in marketing.

\subsection{Data Collection and Analysis}

In view of the fact the aim of all analysis is to write a new research text, in which the research story is told effectively, by creating significant themes that have showed in the research (Crouch \& Pearce, 2012). As previously mentioned this research typically relied on three methods for gathering data: Interviewing in-depth, documentation, and observation. Subsequently, the processes for analysing were in the form of logical order:

firstly, preparation of the data in order to prepare and organize before analysis; the reason why was to gain a chance to replicate recordings, make copies of visuals images and documents such as case report, expert opinion and some picture had taken from different stores to study the shelf impact. 
Second, interpreting the data was after prepared the data and become profoundly understand the data. Interpreting the data involved in four stages: "Code the data, categorize these codes, Identify themes and relationship between the codes and categories, and improve concepts and reach to some generalized statements" (Denscombe, 2007).

Third, verifying the data means checked the validity, reliability, and objectivity of the findings through returned to participant's findings to gain factual accuracy. Finally, representing the data, in this stage, the reader expects to find valuable information.

\section{Findings and Analysis}

Findings are discussed in relation to participant's attitudes towards the factors which influence on the bad image of Doritos chips bags in the marketplace, in addition to this study used two case studies about Doritos bags and Nestle in order to answer on consumer behaviour and the technique of presenting a distinctive package and the function of packaging design. The empirical findings in the two case studies show how food factories deal with packaging design in a promotion circumstance.

\subsection{Findings in the Case Studies}

1). Doritos: Bags of fun derived from Contagious magazine, 2014.

Contagious communications "help branding and advertising companies to understand and adapt to shifts in marketing, consumer culture and technology" (Contagious, 2014). Contagious has three branches over the world: London, New York, and Singapore. Contagious attended a conference in London for the future of direct marketing, the conference talked about Doritos' recent campaigns. On the one hand, Jamie Barrett, the creative director at Doritos, Doritos has been so intelligence through opening a dialogue with customers when the product starts in developing process.

On the other hand, Tom Wasserman, the editor of Brand week said that "I know it's just a corn chip, but it's a very distinctive snack in the world of chips. It's a different shape. You get cheese all over your fingers when you eat it. It has a different smell. It has a stronger taste. People fight over which flavour they like best. It has more attitude than other potato chips. It's the thing you for at $2 \mathrm{am}$. So as passionate as you can be about corn chips, people are passionate. A combination of all these things has meant Doritos has found its way into popular culture". Moreover, Doritos in 2007 said to their customers "Fight for the favour" granting them to choose which new flavour "Wilde White Nacho" or "Smoking Cheddar BBQ". These promotions consider a smart way to contact with your customers and also connect on an individual level with customers by giving customers a voice in the trade mark, furthermore, to create loyalty and gain huge sales.

2). Nestle' derived from Assidoman, 2006.

Nestle' considered one of the world's largest food and Beverage Company and it is take a place in most countries around the globe. In terms of value, chocolate products come in second after coffee products. There is a factory in Hungary called "Diosgyo " $r$ " this factory only produces seasonal products for special occasions such as Halloween, Christmas, and Valentine day. There are many products are known as hollow characters like Santa Claus, Easter bunnies and Easter eggs. Often all products are packed by hand in these occasions.

Every season of these events production operations implemented within a few months. This process is considered magical through dealing with chocolate products. After make confirmation of the storage process, the products are distributed to markets in order to sell these products in short time; it is need accurate speculation of the amount. For instance, there is a product called "Smarties" means the Advent calendar. The temptation of Christmas is usually appealing for children as a result Nestle' realizes the situation and sell these products that come back in various benefits yearly. "Smarties" exceed expectations through the ambiguity Christmas with sales and the chocolate itself is taken an important role in enhance the experiment. The audience for these events is moderate age consumers in different countries such as Finland, Norway, Denmark, Sweden, and Switzerland. Manufacturers and designers create a great harmony between moderate age consumers and their parents, usually parents are spent their money in Christmas time more than any time before.

Lars Wallentin has worked as a chief designer at Nestle said "Nestle' looks for a great balance among how to sell these products and how to attain customer's satisfaction in their products". In addition to the different forms and patterns of the packaging design constantly in various markets, there is a great emphasis on the recognition of the traditional brands. Packaging design should be attractive and safe at the same time. The quality of the chocolate is the same in the calendars. "Nestle' cannot come into terms of quality when it comes to chocolate. It is significant to note that brands as well as costs have to take an appropriate place in the package" said Petr Benda who work as a manager in the department of Application group. "It is a small trick to save some money in 
order to buy a fairly cheap cardboard but without any risk of interruption the packaging in the process of distribution. It is difficult to find time edge for these processes. It is important to acknowledge that coherence and also any obstacles with Fro"vi cardboard which our company has used yearly. A high quality print packaging is considered a strong element in relation to consumers who use our production. An innovative strong cardboard assures that products will arrive in the stores in the same shape and that products will be opened and closed many time for more one month without tearing" says Petr Benda. As a final point, the cardboard material is created by a local transformer Zalai Nyamda Zrt in Hungary.

There is no doubt that renewal and diversity packaging design in the markets has a significant impact on consumers, but the producers have to concentrate on how to success in persuade consumers in your brand, such as Smarties. The packaging design must always communicate with audience and choose a correct time in the year to raises the product in the shops such as Advent calendar. Always should thinking of the obstacles which will face the new package.

\subsection{In-depth Personal Interviews Findings}

For most participants in the interviews, the factors which influence on the bad image of current Doritos chips bags in the marketplace are included in three main functions of packaging:

\section{1) Protection}

The majority of respondents insisted on the importance of maintaining the triangular chips shape from breaks and damage. One participant said that "It is really annoying when I open the bag and let the strong smell of processed cheese powder overwhelm me then when I peek in the package to select the first cheesy chip I feel upset because I see the bag full of crumbs and breaks, I cannot stop thinking about new distinctive package can protect chips from breaks".

The respondents had very similar views; they suggested that to make the new package from strong materials such as plastic box, cardboard triangular prism container, or any heavy material to protect and keep chips so beautifully intact. According to Ken Newton works as a product innovation leader at Salford University said that "If I asked to design new package to protect chips, I will start look for food materials like a pastry and put chips inside it ...., so you can eat it and cover the pastry and chips with thin material ..... As a begging of new design I need to think in use easily recyclable materials or biodegradable materials will be better than anything else.... and the new package should be testing in pending machine".

\section{2) Communication}

Some research studies have reported that the color, illustrations and surface graphics of a packaging design on the supermarket shelf influence the consumers. The majority of respondents prefer Doritos packaging colors, one participant said that "The most thing attract me in Doritos package is colors, Doritos colors give me more energy, enthusiastic and passion". Some participants suggested that keep old packages colors in the new packaging design. Moreover, Color was mentioned frequently in relation to get the consumer buying the production a highly competitive environment. According to the associate professor in marketing said that "Visual attractiveness and capacity of product packaging to attract consumer's attention has an important influence in the purchase decision, in addition to consumer preferences .... Visual communication can increase sales by designing an attractive packaging that will attract consumer's eyes in the shop and pay your attention to this product". An important point is that the responses were strongly agreed with literature review. According to Silayoi and Speece (2004) believe that "lack of graphics in package can waste the sale for many customers. As well as appealing graphics increases the sales as much as possible. For example, the colourful package can appeal consumers to buy".

The associate professor said that "Printed information on the package considers useful for customers and companies .... The printed information must include ingredients, use, warning, dates, price, special offers, manufacturers address, contact information, product title, bar code and more .... Packaging design is a marketing tool can be used by manufacturers to motivate consumers to buy the product".

\section{Conclusion}

The results of the study show that consumers admire the product after they bought these wonderful and appealing packaged products. As a result of these facts, this study cannot say there is an equal relationship between attractive packaging design and fabulous product quality, however, there is affirmative thinking and obvious direction about attractive packaging design shows valuable product quality. As well as unexpected that people are turning into more and more demanding, packaging design is steadily shown the significant role in a way to serve consumer by providing printed information and also presented the functions. There are many 
functions to packaging design in order to ease and communicate with customers; there is no doubt about increasingly important role of packaging as a strategic tool to attract consumers' attention and their perception on the product quality. Packaging has various important functions in the markets from the shelf to the customer. First important function is to protect and store chips in strong materials, this is in line with literature review "Practicality considers the most important part of packaging design, clearly because customers often pick the tried and true route which is a lost opportunity for innovation". Furthermore, in these days customer's needs have also request many requirements on the package. Innovation packages give more value to the products if they meet customer's demands, for example, easy open package, easy store package, easy carry package, use biodegradable materials, and non-breakability.

\section{Recommendation}

After the comprehensive review of the literature and analysis, the study has derived some predictions for the future research endeavours in the field of packaging design. Brand has important role in identify layout, graphics, color, and typeface. The new packaging design mostly uses the brand in products. Mainly, the packaging design includes all printed information such as made it, where it was made, when it was made, what it contains, how to use it. Moreover, some people believe that consumers are precisely planned by brand to use the products. The printed information is given in the brand and its value has to be showed while promoting the product in the market.

\section{References}

Ampuero, O., \& Vila, N. (2006). Consumer perceptions of product packaging. Journal of Consumer Marketing, 23(2), 102-114. http://dx.doi.org/10.1108/07363760610655032

Bone, P. F., \& France, K. R. (2001). Package graphics and consumer product beliefs. Journal of Business and Psychology, 15(3), 467-489. http://dx.doi.org/10.1023/A:1007826818206

Byars, M., \& Gelman, A. (2000). Aspects of Essential Design. Suisse: Rotovision.

Calver, G. (2004).What is packaging design? Switzerland: Roto Vision SA.

Cooper, H. (2010). Research synthesis and meta-analysis: A step-by-step approach (4th ed.). Thousand Oaks, CA: Sage.

Creswell, W. (2009). Research design: qualitative, quantitative, and mixed methods approaches. Los Angeles: Sage.

Crouch, C., \& Pearce, J. (2012). Doing Research in Design. London: Berg.

Denscombe, M. (2007). The Good Research Guide for small-scale social research projects (3rd ed.). New York: Two Penn Plaza.

Denzin \& Lincoln, Y. S. (Eds.). Collecting and Interpreting Qualitative Materials (pp. 130-149). London: SAGE.

Flick, U. (2009). An introduction to Qualitative Research (4th ed.). London: SAGE Ltd.

Garber, L., Burke, R., \& Jones, J. (2000). The role of package color in consumer purchase consideration and choice. Working Paper No. 00-104, Marketing Science Institute, Cambridge, MA.

Gordon, A., Finlay, K., \& Watts, T. (1994). The psychological effects of colour in consumer product packaging. Canadian Journal of Marketing Research, 13, 3-11.

Harper, D. (1998). On the Authority of the Image: Visual Methods at the Crossroads. In N. K. Denzin \& Y. S. Lincoln (Eds.), Collecting and interpreting qualitative materials (pp. 130-149). Thousand Oaks, CA: Sage.

James, S., Hosahalli, R., \& Benjamin, S. (1990). Developments in food packaging technology. Trends in Food Science and Technology, 1(1), 111-118. http://dx.doi.org/10.1016/0924-2244(90)90086-E

John, G. (2000). The ethical consumer moral norms and packaging choice. Journal of consumer marketing, 23(2), 100-112.

MacInnis, D., \& Price, L. (1987). The role of imagery in information processing: Review and extensions. Journal of Consumer Research, 13(4), 473-491. http://dx.doi.org/10.1086/209082

Merriam, B. (2009). Qualitative research: a guide to design and implementation. San Francisco, Calif.: Jossey-Bass. 
Meyers-Levy, J., \& Peracchio, A. (1995). Understanding the effects of color: How the correspondence between available and required resources affects attitudes. Journal of Consumer Research, 22(2), 121-138. http://dx.doi.org/10.1086/209440

Rettie, R., \& Brewer, C. (2000a). The verbal and visual components of package design. The Journal of Product and Brand Management, 9(1), 56-68. http://dx.doi.org/10.1108/10610420010316339

Rita K., Aiste, D., \& Laura, N. (2009), Impact of package elements on the consumer purchase decision economics \& msanagment.

Riversand. (2014). Powering Accurate Product Information. Retrieved from $\mathrm{http}: / / \mathrm{www}$. riversand.com/solutions/pim

Rundh, B. (2005). The multi-faceted dimension of packaging. British Food Journal, 107(9), 670-684. http://dx.doi.org/10.1108/00070700510615053

Schoormans, J., \& Robben, H. (1997). Effect of new package design on product attention, categorization and $\begin{array}{lllll}\text { evaluation. Journal of Economic Psychology, } & \text { 18(2/3), }\end{array}$ http://dx.doi.org/10.1016/S0167-4870(97)00008-1

Silayoi, P., \& Speece, M. (2004). Packaging and purchase decisions: An exploratory study on the impact of involvement level and time pressure. British Food Journal, 106(8), 607-628. http://dx.doi.org/10.1108/00070700410553602

Silayoi, P., \& Speece, M. (2007). The importance of packaging attributes: A conjoint analysis approach. European Journal of Marketing, 41(11/12), 1495-1517. http://dx.doi.org/10.1108/03090560710821279

Smith, P., \& Taylor, J. (2004). Marketing Communications (4th ed.). London: Minshull.

Sogn-Grundvag, G., \& Ostli, J. (2009). Consumer evaluation of unbranded and unlabelled food products: the case of bacalhau. European Journal of Marketing, 43(1/2), 213-228. http://dx.doi.org/10.1108/03090560910923300

Stake, R. (2008). Qualitative case studies. In N. Denzin \& Y. Lincoln (Eds.), Strategies of qualitative inquiry (3rd ed., pp. 119-150). Thosand Oaks, CA: Sage Publications.

Thurmond, V. (2001). The point of triangulation. Journal of Nursing Scholarship, 33(3), 254-256. http://dx.doi.org/10.1111/j.1547-5069.2001.00253.x

Underwood, R. L., Klein, N. M., \& Burke, R. R. (2001). Packaging communication: attentional effects of product imagery. Journal of Product \& Brand Management, 10(7), 403-422. http://dx.doi.org/10.1108/10610420110410531

Wolff, S. (2004). Analysis of Documents and Records. In U. Flick, E. V. Kardorff, \& I. Steinke (Eds.), A Companion to Qualitative Research (pp. 284-290). London: SAGE.

Yin, R. K. (2003). Case study research: Design and methods (3rd ed.). Thousand Oaks, CA: Sage.

\section{Copyrights}

Copyright for this article is retained by the author(s), with first publication rights granted to the journal.

This is an open-access article distributed under the terms and conditions of the Creative Commons Attribution license (http://creativecommons.org/licenses/by/3.0/). 